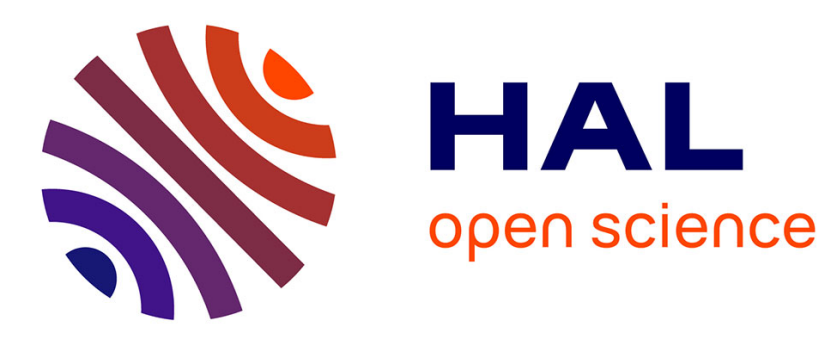

\title{
Design for Additive Manufacturing: Supporting Intrinsic-Motivated Creativity
}

Anne Lise Rias, Carole Bouchard, Frederic Segonds, Benjamin Vayre, Stéphane Abed

\section{- To cite this version:}

Anne Lise Rias, Carole Bouchard, Frederic Segonds, Benjamin Vayre, Stéphane Abed. Design for Additive Manufacturing: Supporting Intrinsic-Motivated Creativity. Emotional Engineering, 2017, pp.99-116. 10.1007/978-3-319-53195-3_8. hal-01651570

\section{HAL Id: hal-01651570 https://hal.science/hal-01651570}

Submitted on 29 Nov 2017

HAL is a multi-disciplinary open access archive for the deposit and dissemination of scientific research documents, whether they are published or not. The documents may come from teaching and research institutions in France or abroad, or from public or private research centers.
L'archive ouverte pluridisciplinaire HAL, est destinée au dépôt et à la diffusion de documents scientifiques de niveau recherche, publiés ou non, émanant des établissements d'enseignement et de recherche français ou étrangers, des laboratoires publics ou privés. 


\title{
DESIGN FOR ADDITIVE MANUFACTURING: SUPPORTING INTRINSIC-MOTIVATED CREATIVITY
}

\author{
Anne-lise Rias ${ }^{1,2}$, Carole Bouchard ${ }^{1}$, Frédéric Segonds ${ }^{1}$, Benjamin Vayre $^{2}$, \\ Stéphane Abed ${ }^{2}$
}

\begin{abstract}
Emotional aspects and designers' motivations in Design For Additive Manufacturing are rarely studied. Still, as they can influence creative behaviors, it is worth of interest to draw some bases for a relation between designers' motivations and the field of Additive Manufacturing. This paper aims at identifying the motivations that push designers to deal with AM in their practice. We have highlighted that they experience some extrinsic motivations: technical improvements, economics and social environments pressures. We also notice that creative designers, apart from AM, usually experience some intrinsic motivations and, moreover, that it exists an ideal state to generate creative concepts: the Flow. To support creative designers in DFAM in reaching the Flow, we then identified 4 key levers through the potential of AM: the newness of AM processes, the needed skill of 3D modelling, the investigation of new shape grammars and finally the opportunity of embodying concepts into physical objects. To benefit from this potential, we assume that designers' intrinsic motivations should be supported: we identified three required conditions. The first one is the use of a proper vocabulary i.e the expression Additive Manufacturing instead of $3 D$ Printing. The second one is the development of a design process which integrates a creative approach. The third condition is the use of AM objects as experience triggers during creative sessions to arise positive emotions.
\end{abstract}

\section{Introduction}

At first motivated by the expansion of Additive Manufacturing (AM) through various industries and its impacts on designers' activities, we focused our research on Design For Additive Manufacturing (DFAM) methods. In a previous state-of

1. Laboratory of product design and innovation 151 Boulevard de l'hôpital 75013 Paris anne-lise.rias@ensam.eu

2. Poly-Shape SAS

235 Rue des Canesteu 13300 Salon-de-Provence 
the-art of existing methods [1] we noticed that they are limited regarding supporting designers' creativity. In order to enhance creativity in DFAM, this paper aims at identifying the motivations that push creative designers to integrate AM in their practice. We first highlight that creative designers are experiencing some extrinsic motivations: technical improvements, economic and social environments are all reasons which push designers to deal with AM.

But secondly, as literature is rich about creative behaviors analysis, we also notice that creative designers usually experience some intrinsic motivations and, moreover, that it exists an ideal state to generate creative concepts: the Flow. To support creative designers in DFAM in reaching the Flow, we then propose to identify the potential of AM regarding intrinsic motivations.

To benefit from this potential, we assume that designers' intrinsic motivations should be supported to reach the best conditions to generate creative concepts. We identified three required conditions. The first one is the use of a proper vocabulary i.e the expression Additive Manufacturing instead of $3 d$ Printing. The second one is the development of a design process which integrates a creative approach. We present our creative-DFAM process for that purpose. The third condition is the use of AM objects as experience triggers during creative sessions to arise positive emotions such as surprise and playfulness.

\section{The Additive Manufacturing expansion}

In our study, personal $3 \mathrm{~d}$ printers and educational uses are not considered, we focus on industrial applications of AM.

\subsection{Historical and current extrinsic motivations}

Grouping twenty different manufacturing processes, Additive Manufacturing is rooted in a thirty-year-old technical background [2] [3]. Along with the technical improvements of the different processes and materials, AM has gradually penetrated through several industrial sectors such as Aeronautics and Space, Motor sports, Military, Medical, Jewelry and Consumer products and electronics [4]. AM integration in industries is even more progressing since some processes allow to produce with metallic alloys (since 2000's). Indeed, beyond rapid prototyping, 
processes such as Laser Beam Melting or Electron Beam Melting build products which are not prototypes but fully functional and ready to use.

This technology-pushed paradigm is currently nourished, in various industries, by economic, marketing and social motivations. Economic motivations are various, we highlight here some of the most significant. Using AM, molds and specific tooling are not necessary any more. In other words, this technology allows industries to save some money usually dedicated to project development and production. As a 3D file is the only necessary input data, AM is often applied to projects subjected to strong time pressures. For example, the Motorsport industry particularly benefits from this advantage: mechanical parts are produced and delivered according to the needs of racing teams during the few months of a racing season. AM is also enhancing the development of an industrial spare parts market. When it is possible, reusing and repairing parts instead of replacing them is a strong economic motivation for several industries. For example, the Laser Metal Deposition process has this specific advantage: it allows to repair damaged parts, often turbine blades for Aeronautics.

Customer satisfaction is an important marketing motivation which also contributes to explain additive manufacturing's expansion. Based on a digital workflow only, AM allows to produce unique parts for patient specific needs and anatomy such as implants, prosthetics and surgical guides. Indeed, the Medical industry often uses this advantage of custom-made solutions. Custom-made solutions are also popular in other industrial fields with specific requirements such as Space and Military.

Social motivations are less studied and numbered but they are worth to be mentioned as a contribution to the expansion of AM. In our competitive world, industrial companies have divisions dedicated to the exploration of new processes. For them, being at the cutting edge can make the difference. In many industries, AM is still considered as a new technology which has to be learnt, experimented and integrated. An obvious example of this trend is the flourishment of a range of theoretical and practical courses, offered by different private and public organizations. In France, more than 10 different training offers are currently available [5].

The cited motivations are rooted in technical, marketing, economics and social environments. In this sense, they are extrinsic motivations which push designers to integrate Additive Manufacturing. Indeed, their activities are directly impacted by AM: new opportunities and constraints in terms of geometries, new development times, new materials, new knowledge to integrate and other consequences. Design 
Research is currently supporting this paradigm with the development of new design methods. These methods, grouped under the name Design For Additive Manufacturing (DFAM), are summarized in the following section.

\subsection{Impacts on design methods: the development of}

\section{DFAM}

As the specific orientation of Design For X (DFX) for the AM paradigm, DFAM groups methods that are intended to manage the required knowledge about product, process and material as soon as the beginning of the product lifecycle i.e the socalled early stages of the design process [6]. Opportunistic DFAM methods guide designers to take into account AM specificities, such as the geometrical and material distribution freedoms, from the beginning and during the design process. These methods lead them to the creation of IRs [7, 8]. Other methods, called Restrictive consider AM limits and define criteria, such as manufacturability and cost, to evaluate the IR regarding AM specificities [9] [10]. They guide designers to progress from an ideal IR to realistic ones by embodying variations due to the manufacturing constraints. The $3^{\text {rd }}$ category Dual DFAM groups methods combining the two previous approaches [11]. Dual DFAM is more suitable for product innovation since it guides designers to exploit AM potential in a realistic way. Indeed, by conducting as soon as early stages both IR creation and IR evaluation, these methods help avoiding late design changes which cause extra cost and longer development time. However according to the cited authors, Dual DFAM methods currently represents less than $30 \%$ of existing DFAM methods.

Conducting a state of the art of existing DFAM methods, it appeared that they are limited regarding the integration of a creative approach. We identified that Dual $D F A M$ methods have different approaches to process from input data to the creation of an initial IR. We proposed to categorize them in 3 levels as we noticed, through the qualities of the generated initial IR, 3 levels of changes: Level 1 - Formal newness, Level 2 - Functional reconfiguration and Level 3 - Form \& Function implementation [1]. Dual DFAM methods follow 3 strategies which already integrate some creative approaches and creativity tools, and thus generate some creative outputs. We compared the 3 strategies and the qualities of the generated concepts in a summary table (see table 1 below). The main result of this comparison is that the existing Dual DFAM methods guide designers to generate only partially creative concepts while fully creative concepts are suitable for a more radical innovation than incremental innovation [12]. We deduced that the development of 
a creative approach to be integrated in DFAM methods could enhance the generation of fully creative concepts.

Table 1 Summary table comparing the DFAM strategies and their generated concepts qualities of the 3 identified levels

( $\mathrm{X}=$ No newness, $\mathrm{O}=$ Newness)

\begin{tabular}{|c|c|c|c|c|}
\hline \multicolumn{2}{|c|}{$\begin{array}{l}\text { Generated concepts } \\
\text { qualities }\end{array}$} & Level 1: Formal newness & $\begin{array}{l}\text { Level 2: } \\
\text { Functional } \\
\text { reconfiguration }\end{array}$ & $\begin{array}{l}\text { Level 3: AM F } \\
\text { \& F } \\
\text { implementation }\end{array}$ \\
\hline \multicolumn{2}{|c|}{$\begin{array}{l}\text { DFAM methods } \\
\text { authors }\end{array}$} & {$[13],[14],[15],[16],[17],[18]$} & {$[19,20],[21]$} & {$[22],[23]$} \\
\hline \multirow[t]{2}{*}{$\begin{array}{l}\text { New } \\
\text { what }\end{array}$} & $\begin{array}{l}\text { Functions } \\
(25 \%)\end{array}$ & $\mathrm{X}$ & $\mathrm{X}$ & $\mathrm{O}$ \\
\hline & Forms $(25 \%)$ & $\mathrm{O}$ & $\mathrm{O}$ & $\mathrm{O}$ \\
\hline \multirow[t]{2}{*}{$\begin{array}{l}\text { New } \\
\text { to }\end{array}$} & $\begin{array}{l}\text { AM industry } \\
(25 \%)\end{array}$ & $\mathrm{O}$ & $\mathrm{X}$ & $\mathrm{X}$ \\
\hline & $\begin{array}{l}\text { Conventional } \\
\text { industry } \\
(25 \%) \\
\end{array}$ & $\mathrm{O}$ & $\mathrm{X}$ & $\mathrm{O}$ \\
\hline \multicolumn{2}{|c|}{$\begin{array}{l}\text { Level of newness } \\
\text { allowed by the } \\
\text { methods (max. } 100 \% \text { ) }\end{array}$} & $75 \%$ & $25 \%$ & $75 \%$ \\
\hline \multicolumn{2}{|c|}{$\begin{array}{l}\text { Realistic to AM } \\
\text { capabilities }\end{array}$} & $\mathrm{O}$ & $\mathrm{X}$ & $\mathrm{O}$ \\
\hline
\end{tabular}

As creative approaches are still poorly studied and integrated in existing DFAM methods, the focus is also rarely centered on additive manufacturing and creative designers' motivations. Without mentioning the specific paradigm of DFAM, it has been recognized that creative designers have different types of motivations (see the following section). Focusing on DFAM, it might be interesting to question creative designers' motivations and their roots. 


\section{Creative designers' intrinsic motivations}

\subsection{General definitions}

According to Ryan and Deci [24], the notion of Motivation is composed of intrinsic motivation and extrinsic motivation. Human beings in general experience extrinsic motivation when the action is initiated by one or a combination of external circumstances such as the expectation of a reward, the feeling of a social pressure, a punishment or others. In opposition, intrinsic motivation means that individuals are conducted to an act only by the interest and the pleasure that they find or think they will find in doing it. It is then distinct from the other cited circumstances. Intrinsic motivation is related to the field of emotional engineering in the way it influences the emotional processes which occur during design activities. Even if current research in emotional engineering is more focused on the end-users, it may also concern the designers themselves. Indeed, in design sciences, emotional aspects have been measured especially when researchers want to enrich designers' experience through new design methods and tools and when they want to assess designers' activities [25].

In design activities, intrinsic motivation modifies designers' experience in a decisive way. Indeed, it is related to inherent satisfaction and pleasure felt during some activities such as: playing, creating, and generating ideas. This type of activities is very familiar to creative designers both in research and professional contexts. In other words, intrinsic motivation concerns, not only but certainly creative designers. To complement the definition of intrinsic motivation, it may be noticed that it is more specifically related to inspiration, energization and activation, through the experience of positive emotions. Furthermore, intrinsic motivation is a crucial mechanism for an open and agile cognitive development since it is the driver of spontaneous exploration and curiosity [26]. Consequently, it impacts the learning processes, therefore the knowledge management processes and finally the idea generation processes. Moreover, on this point, intrinsic-motivated behaviors have been recognized as being more creative, having a greater persistence in the face of adversity and a better focusing.

Considering this definition, we assume that designers' intrinsic motivation and especially their curiosity, may be ignited by adequate stimuli which can be, as presented later in this paper, intermediate objects made with additive manufacturing. In this case, these objects must be open enough to enable tasks such 
as divergent thinking and new concepts generation, but close enough to cope with additive manufacturing requirements. This issue represents a challenge at the moment and for the future, in the way that it can contribute to draw innovative ways of exploiting additive manufacturing.

\subsection{The ideal state of Flow: definition}

Emotional engineering approaches consider emotions in engineering design activities [27]. Even if these approaches mainly focus on evaluating the end-users experience, some studies addressed the emotional state of the designers themselves. From these studies appeared the notion of Flow. Flow is linked to the designers' emotional states and so to his/her intrinsic motivations. [28] [29].

Csikszentmihalyi identified 4 main conditions which can lead to the state of Flow. The first condition is the perceptual response, the second one is the emotional response, the third is intellectual response and the fourth is the communicative response. Extended definitions of these four conditions are beyond the scope of this paper, we focus here on their relations with intermediate objects and representations. The perceptual response is directly related to the objects or representations that designers build and share along to the design processes [30]. It depends on the nature, the shapes and the information embodied in the intermediate objects or representations. We retain that the level of novelty they convey strongly impacts the perceptual response of designers. Secondly, the emotional response, which is activated during design tasks, and the emotional intensity over the emotional states is also partly driven by the interaction with intermediate objects and representations. Thirdly, the intellectual response includes the understanding of the phenomena presented to designers through intermediate objects and representations and the experience of imagining, interpreting, and rebounding with them. Finally, the communicative response is more related to the social aspects related both to group of participants in the context of a creative session and to the work to be done. All the cited conditions are part of intrinsic motivations. Intrinsicmotivated designers can then experience some specific emotions such as curiosity, excitation and surprise. In a more recent study, Ocnarescu summarized the Flow as a specific state characterized by a high intrinsic motivation and the experience of positive emotions with a high intellectual pleasure [29].

According to these definitions, the Flow seems to represent, for creative designers, the ideal state to be reached. We contextualize our assumption in a collective 
creative design context. In this context, we assume that the nature and the qualities of intermediate objects and representations, if they are brought to designers in a playful way, can lead to responses of mixed cognitive constructs. We then assume that these mixed responses can enhance the generation of a bigger number and more creative concepts. As a second effect, we assume that it may also improve the social cohesion between engineers and industrial designers by making the technical knowledge more explicit and easy to share.

In the context of a group creative session, we understand that the intermediate objects and representations have a strong influence on the ability to reach the ideal state of Flow. Indeed, by supporting intrinsic motivation and driving to the experience of positive emotions they represent some of the required conditions to reach the Flow. Focusing on DFAM, we identify, in the following section, the potential of AM to support the quest of the Flow.

\subsection{The potential of Additive Manufacturing regarding}

\section{the Flow}

The previous section 2.1 Historical and current motivations mentions the technical, economics marketing and social environments of additive manufacturing as extrinsic motivations for designers. Section 3 highlights that, apart from AM, creative designers also usually experience intrinsic motivations and that the state of Flow represents the ideal state to be reached for the generation of creative concepts. We then assume that creative designers in DFAM can also experience some intrinsic motivations, positive emotions and intellectual pleasures which are specific to additive manufacturing characteristics.

As intrinsic motivations are more individual experiences than a standard phenomenon, it would require an extended experimental study on designers' activities supported by emotional engineering research. However, we here suggest 4 key levers we found embodied in additive manufacturing itself.

The first lever is the relative newness of additive manufacturing. Regarding industrial processes history, AM is still quite new. It has, in total, a 30 years-old background while milling or foundry have been mastered for several decades. We assume that this newness tickles designers' curiosity and that they feel the need to satisfy that curiosity by, at least, being interested in the theory of AM if not trying to investigate it in practice. We assume that satisfying his/her curiosity contributes 
to the experience of positive emotions and that it is a motivation to be spontaneously interested by AM.

The second lever is related to one specific characteristic of AM: it is entirely based on a digital workflow. To be more specific, using AM requires skills of a high level in $3 \mathrm{D}$ modelling. In other words, designers have to exercise their skills for virtual representations. We assume that achieving complex virtual representations contributes to the experience of a high intellectual pleasure.

The third lever directly follows the first and second levers: being an expert in 3D modelling allow designers to investigate new shape grammars [31]. We assume that investigating new shape grammars contributes to the experience of both positive emotions regarding newness and a high intellectual pleasure regarding the achievement of complex activities. In this sense, designers could be motivated to investigate AM because they want to satisfy their curiosity and find pleasure in achieving complex tasks. We assume that this lever enhances a high intrinsic motivation.

The fourth lever is also related to a specific characteristic of AM: based only on a 3D file, this technology allows to rapidly obtain a physical embodiment of a virtual concept, an object. As 3D models exist only virtually, they can be rapidly expanded or modified. Consequently, while investigating AM, designers keep a constant relation between physical objects and virtual representations. We assume that this characteristic contributes to satisfy designers' need of feeling their concept in real by experiencing textures, weights, dimensions, colors and kinematics. We assume that experiencing in real, by the manipulation of objects, is a playful activity which contributes to the experience of positive emotions.

Considering the cited 4 key levers, we can assume that AM has itself great potential to guide designers to reach the ideal state of Flow. Indeed, its specific characteristics could contribute to the experience of a high intellectual pleasure, positive emotions and a high level of intrinsic motivations.

However, as the question of how to reach the Flow is not yet an approach integrated in DFAM methods, we assume that intrinsic-motivated creativity for DFAM would require some conditions. Through the cited potential of AM, we identified 3 conditions: designers should be guided to use the proper vocabulary regarding technologies (section 4), their activities should be supported by a design process oriented to the generation of creative concepts (section 5) and enhanced by using objects as experience triggers (section 6). 


\section{First condition: $3 D$ printing or Additive Manufacturing, using the proper vocabulary}

The vocabulary may be considered something trivial. We assume that the choice between $3 D$ Printing or Additive Manufacturing is not. It may indicate the level of expertise regarding these technologies but more importantly the motivation, for designers, to integrate these techniques in their practice.

\subsection{The role of semantics}

Firstly, it should be noticed that the expression $3 D$ Printing has been patented by an American private company. It is frequently used to describe projects made by the Material extrusion process, with plastic filaments on the small printers we can now have on a desk. It is also used to describe projects made either with Stereolithography or Selective laser sintering. However, the strict definition of $3 D$ Printing, as patented, describes precisely the Binder jetting process. This technology is based on jetting, through cartridges, a glue and colored inks on a white sheet. The resemblance to the familiar 2D printing on paper sheets might have promoted the use of $3 D$ Printing by a wide range of people.

From a semantic point of view, choosing $3 D$ Printing instead of Additive Manufacturing means ignoring the European and American studies which produced the standards NF E 67-001 and ISO/ASTM 52900-15. Previous literature presented, along to the technical improvements, various categorizations according to the materials, the energy sources or the applied transformations [32]. In order to standardize vocabulary and definitions, it is now defined that Additive Manufacturing groups all the processes which allow to produce, layer by layer, by the addition of material, a physical object from a digital file [2]. The standards categorized 7 type of processes. Regarding how to title each process, definitions are still under discussion. For example, the title Selective Laser Melting is often used but, as it is propriety of a private company, standards switched to Laser Beam Melting. From a designer point of view, it is necessary to investigate these techniques, in theory and in practice, to avoid getting lost through all the available definitions. 


\subsection{Confronting the technologies}

At the time when $3 D$ Printing was not yet a familiar expression, communications for a wide audience were organized along to the technical improvements, especially visible in the USA. For example, Stereolithography were presented in 1989 by 3D Systems in the famous American TV show Good morning America [33]. In this sense, it is not certain that simplifying Additive Manufacturing into $3 D$ Printing is a benefit for the integration of the different technologies into designers' practices.

Using $3 D$ Printing also means disregarding the historical roots of these technologies that draw upon Topography and Photosculpture from the $19^{\text {th }}$ century. More than 20 patents, focused on the processes themselves, have been registered [34] as well as dozens of patents about 30 years of industrial applications of additive processes.

Using $3 D$ Printing also means focusing on a portion reduced to $20 \%$ of the wide range of different additive processes, which counts in total 20 processes, developed until 2010. From a creative designer point of view, focusing only on some processes makes invisible some new opportunities as, for example, designing to produce products (not prototypes but finished parts) out of metal with the Laser Beam Melting process. Sticking to $3 D$ Printing is also a disadvantage in taking into account the latest technical developments (reliability, costs, fastness, range of material...) that scale additive technologies to an industrial productivity level.

Finally, using $3 D$ Printing stifles one of the intrinsic motivation for creative designers while Additive Manufacturing favors the adoption of these technologies.

\section{Second condition: a creative approach for early stages of DFAM}

To guide designers to reach the Flow, we assume that their activities should be supported by a creative approach to be integrated in the early stages of DFAM methods.

\subsection{Purpose of the creative approach}

Creative designers use sources of inspiration as input data to stimulate ideas production. They gather visual and textual information to get inspiration about 
features that could be, by analogical or case-based reasoning, implemented in the product to be designed [35] [36]. In the same way, they also use precedents. By being examples of existing solutions, artifacts, graphical and textual information embody design knowledge which activates the designer's personal knowledge. Recently activated knowledge is used to generate ideas [37]. According to Bonnardel [38], inspirational examples can be found within the product domain (i.e intra-domain), in this case within AM processes and AM products background. They also can be found far from these domains (i.e far-domain examples). Some existing DFAM methods showed that inspiration from intra-domain leads to partially creative concepts while some others, inspired by far-domain examples also guide to partially creative concepts. Therefore, we assume that our approach must rely on associations between intra-domain examples and far-domain examples. Thus, our method intends to foster designers' creativity by crossing AM examples with other domains examples. The goal of this forced association is to extend the design space to new possible concepts. Based on this approach, we propose a method called Creative-DFAM.

\subsection{Framework of the proposed Creative-DFAM method}

This 5 stages Creative-DFAM method is rooted in Maidin's [23] approach but with the integration of other domains examples inspiration. The forced and systematic association of 2 different domains examples is inspired by the work of Yoon [39] on morphology analysis to forecast R\&D opportunities. The method can be used by both engineers and industrial designers who already have some knowledge about AM processes. It is intended to impulse R\&D collaborations between designers and industrial stakeholders interested in emphasizing the use of AM in the industrial sector they work for. We specify that this method is dedicated to AM design projects only, not to projects where the choice between AM or conventional processes is not yet done. The method starts when general design specifications are available, it is represented in figure 1 below. To illustrate our method, we propose an example: the generation of a creative AM concept of a turbine blade (figure 2 below). 


$\begin{array}{lllll}1-\text { FEATURES } & 2- & 3-\text { IDEAS } & 4-\text { CONCEPT } & 5 \text {-CONCEPT } \\ \text { DISCOVERY } & \text { EXPLORATION } & \text { EVALUATION } & \text { GENERATION } & \text { EVALUATION }\end{array}$

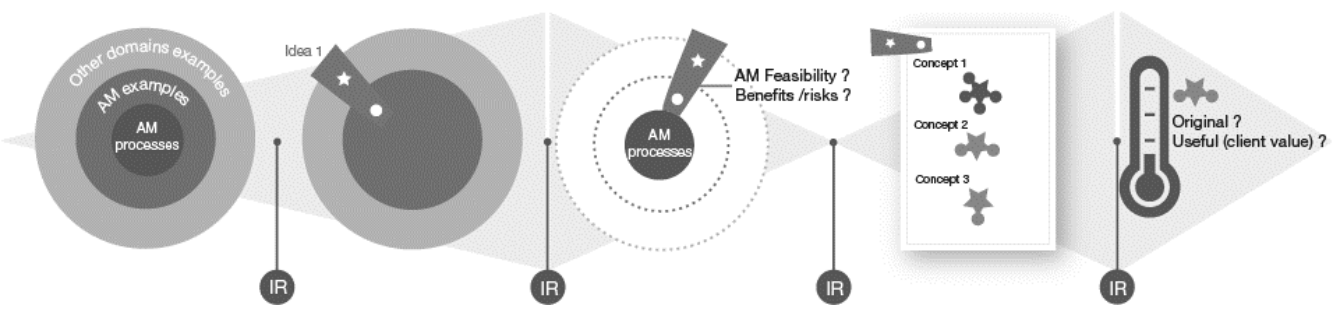

Fig.1 The proposed Creative-DFAM method

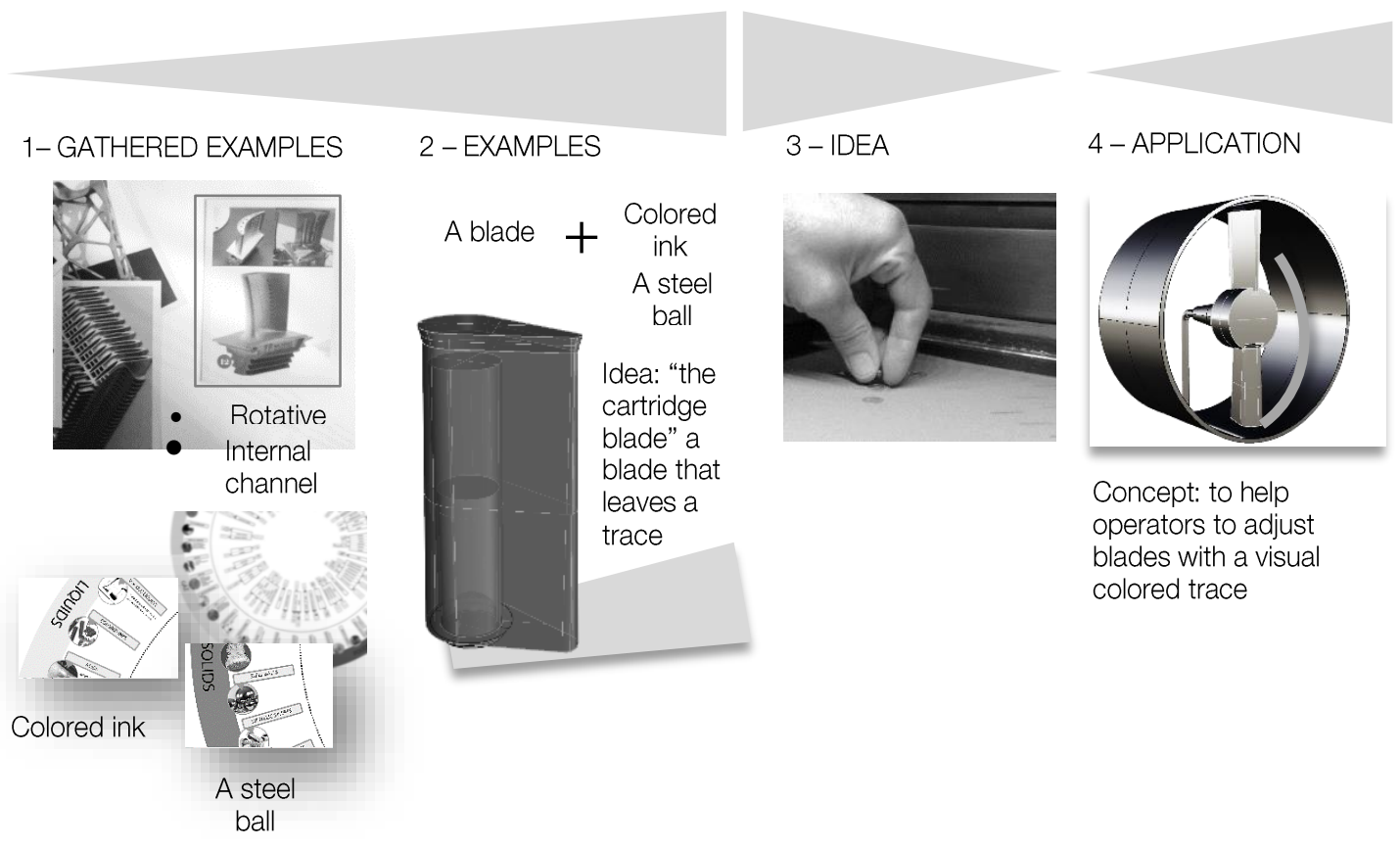

Fig. 2 Example of a generation of a creative AM concept following the Creative-DFAM steps

1/ Features Discovery (figure 1 stage 1) - The first task for R\&D designers is to gather examples of AM products (i.e features already realized in AM) and other 
domains examples (i.e features not yet realized in AM). The examples can be represented by pictures, words or artifacts. The purpose of this stage is to have a great view of what has been done and what can still be created. The survey has to be regularly enriched to update the two taxonomies. Then, designers name the examples' features with keywords and 3D model these features in a simplified and editable manner. In the showed illustration (figure 2 stage 1) a turbine blade is identified among others as a product already realized in AM. It is described by two keywords: ROTATIVE and INTERNAL CHANNEL. Two others domains examples COLORED INK and A STEEL BALL have been identified, among others, as not yet linked to AM. Their features are named LEAVE A TRACE and ROLL. As an output, designers form an extended portfolio of examples.

2/ Exploration (figure 1 stage 2) - This stage consists in randomly and systematically associating an example of one wheel to an example of the other wheel. In other terms, designers conduct forced associations of AM examples with OD examples in order to generate ideas. At least one idea should be formulated for each association. For example (figure 2 stage 2), blade's features are associated to colored ink and steel ball features to generate the idea of a blade that integrates a colored ink in its internal channel and a steel ball at the end of it in order to leave a trace when it's rolling. As being similar to a cartridge, the idea is called "the cartridge blade". The idea is represented by modifying the input simple 3D model. The output of this stage is a case-base of various and numerous ideas that present potential opportunities for collaborative $R \& D$.

3/ Ideas evaluation (figure 1 stage 3) - A first idea evaluation is conducted by AM experts. The generated ideas are faced to AM processes in order to scale the ideas at a mature level i.e they are feasible with current AM processes or an emergent level i.e potentially feasible if AM processes improve. Some associations could be evaluated as impossible due to major technical limit or technical risk. The association would be then eliminated. The proof of the ideas feasibility is established by actually additively manufacture them as shown in figure 2 stage 3 . This stage leads to a reduced portfolio of ideas embodied in artifacts.

4/ Concept generation (figure 1 stage 4) - The artifacts and their manipulation stimulates analogical reasoning to translate the previous ideas into concepts which show application scenarios. As shown in our example (figure 2 stage 4), the scenario of a "cartridge blade" used to help operators in adjusting rotative blades has been formulated. The blades should leave a constant and uniform trace on the support if they are well aligned. This stage is conducted by designers in a co-design approach with industrial stakeholders to enhance the formulation of concepts with a high 
client value. This stage output is a base of concepts sheets describing potential products to be developed for industrial sectors.

5/ Concept evaluation (figure 1 stage 5) - The purpose is to identify the concepts to be further detailed and optimized in downstream DFAM stages. The required profiles for the evaluation are experts of AM who have a good understanding of industrial sectors where AM is integrated, such as innovation managers, senior designers and trade engineers for example. They are asked to say how much the generated concepts are: 1/ Original (in the sense of new) regarding traditional products of the involved industrial sector and regarding AM industry, 2/ Useful regarding the involved industrial sector (client value), 3/ Realistic regarding AM capacities. Following our example, the "cartridge blade" is considered new since it integrates new functions and forms, and since the associated features have not been already realized in AM industry (see table 2 below).

Table 2 Originality evaluation of the example concept "Cartridge blade"

\begin{tabular}{|lll|}
\hline New what & Functions (25\%) & $\mathrm{O}$ \\
\cline { 2 - 3 } & Forms (25\%) & $\mathrm{O}$ \\
\hline New to & AM industry (25\%) & $\mathrm{O}$ \\
\cline { 2 - 3 } & $\begin{array}{l}\text { Conventional industry } \\
(25 \%)\end{array}$ & $\mathrm{O}$ \\
\hline Level of newness of the concept & $100 \%$ \\
\hline
\end{tabular}

\section{Third condition: using objects as experience triggers}

Intermediate objects and representations are created all along the design processes. We assume that using intermediate objects as experience triggers contributes to the experience of positive emotions such as playfulness.

\subsection{Background regarding Intermediate Representations in DFAM}

In a previous experimentation we have noticed that there is a gap between designers' intentions and the information embodied in the created intermediate representations [40]. It is especially true when designers want to represent complex features and when it is about representing kinematics. Even if the results of this experimentation 
are still under confidentiality, we can notice that participants have expressed the limits of keywords to describe evolving features while these ones are the most typical of AM and of static representations while these ones showed a great potential for innovation. The lack of interaction between designers and the representations appeared. They also expressed the limits of 3D modelling while they wanted to experiment kinematics and to share their ideas within the groups. This gap raises the need for a new kind of intermediate representations in early stages of creative design for additive manufacturing.

Research work of Mer et al. [41] specified the role of Intermediate Objects in early stages of creative design with the notion of Open-ended objects in opposition to Closed objects. Indeed, physical objects such as mock-ups and prototypes are often used by designer teams to validate some design solutions. These objects are not intended to be modified, they are then closed [42]. On the contrary, Open-ended objects are made to be indefinitely modified because they are not meant to embody design solutions. They have four main purposes. Open-ended objects create a shared experience in the beginning of creative design processes that will infuse in designers' minds during creative sessions. Secondly, they are not exactly objects since they should be quite abstract, minimalist and simple. Thirdly, they should be functional so designers can observe, try and feel, in other words, experience. Finally, they are a tangible translation of the brainstorming brief. In other words, they are a medium to explore the questions through experience rather than through language. They are then meant to be useful in multidisciplinary design teams.

We assume that using experience triggers during group sessions is a way to support intrinsic motivated designers. According to the specific characteristics of AM (see section 3.3), producing objects with AM could allow designers to experience their concepts through tangible characteristics by manipulating the objects. Based on the cited definitions, we initiate in the following section a conceptual definition of this objects that could play a role of experience triggers to enhance the experience of playfulness and more generally positive emotions. This approach, as well as the objects themselves are called AMIO for Additive Manufacturing of Intermediate Objects. 


\subsection{Objects as experience triggers in Additive Manufacturing}

We propose a conceptual definition of AMIO in a creative DFAM approach. AMIO are meant to be at the crossing point between closed and open-ended objects. Figure 3 below shows that AMIO are part of the Intermediate Representation sequence illustrated by an example of the generation of a new function for turbine blades. We assume that AMIO could foster the generation of AM creative concepts as it can play the role of a mediation to ease the collaboration between AM designers and industrial experts from several industrial sectors.

As the digital workflow of DFAM needs 3D virtual models as input data, the objects can be easily manufactured from the IR $n^{\circ} 2$. AMIO thus create a link between a virtual experience of an idea and a tangible experience of it: they are easily manually actionable (see IR $\mathrm{n}^{\circ} 3$ on figure 3 ). Through sensory manipulation, AMIO are to be used to introduce creative concepts generation sessions. For example, on figure 3 (IR $n^{\circ} 4$, the last one), designers generated a concept of rotating blades filled in with a viscous liquid used to check the alignment of the blades. They phrased that this function "could be integrated in test bench turbine blades". 


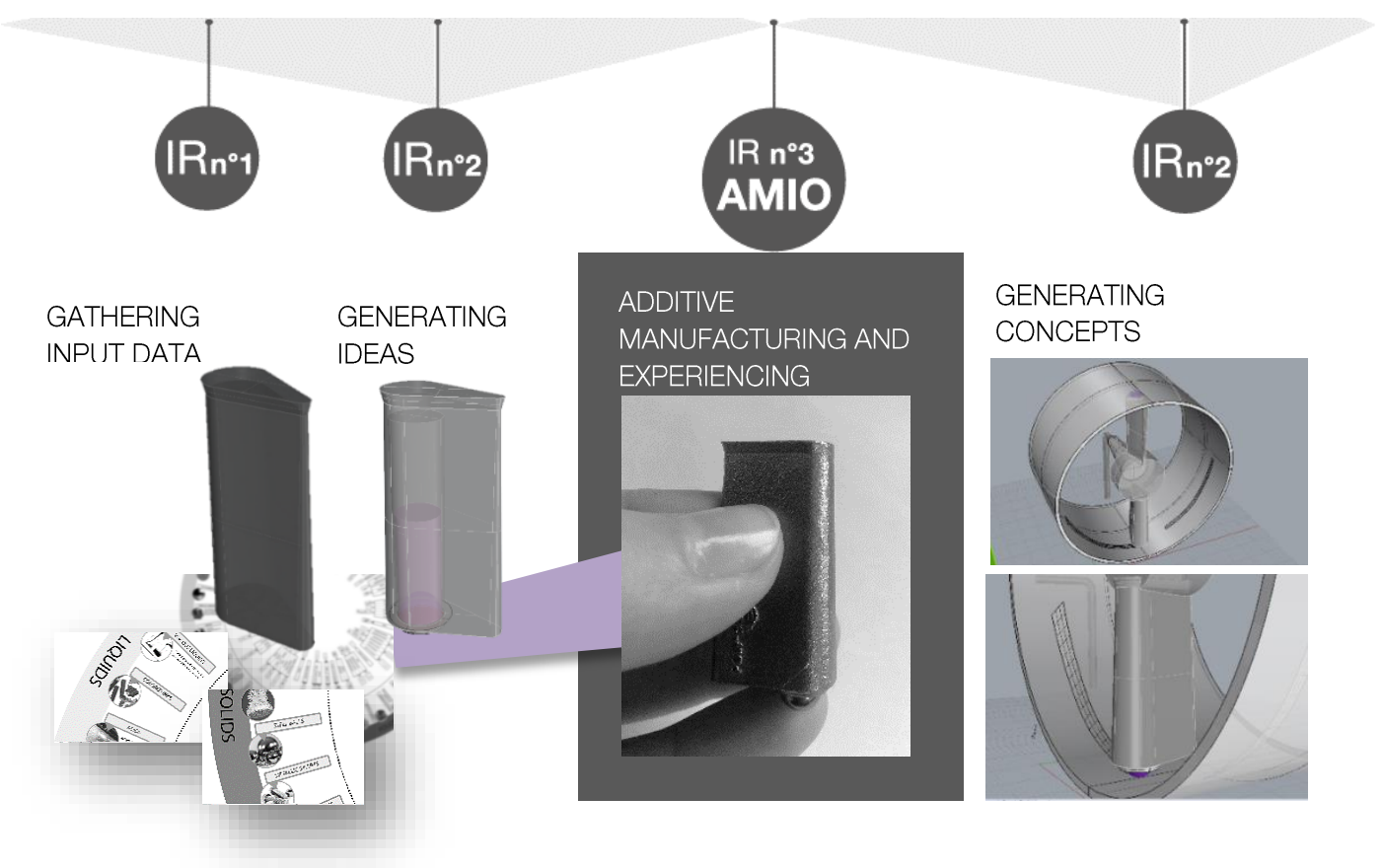

Fig.3 Intermediate Representation sequence integrating AMIO

According to Cruz recommendations, AMIO are abstracted enough to not be understood as a product mock-up or prototype. The different design stakeholders can interpret and diverge upon the objects to generate different concepts. In this sense, AMIO are open-ended objects. However, by being actually additively manufactured with the same processes and materials that could be used for the final product production, AMIO also play the role of an early technical validation of the generated idea. If the idea is not realistic enough regarding AM specificities, it won't be manufacturable. Being tangible objects actually made with AM, AMIO could also contribute to give the idea more credibility to the eyes of industrial experts. In this sense, AMIO are also closed objects. 


\section{Conclusion}

Emotional aspects and designers' motivations in Design For Additive Manufacturing are rarely studied. Still, as they can influence creative behaviors, it has been interesting to draw some bases for a relation between designers' intrinsic motivations and the specific field of Additive Manufacturing.

This paper aimed first at identifying the motivations that push designers to deal with AM in their practice. We have highlighted that creative designers are experiencing some extrinsic motivations: technical improvements, economic and social environments are all reasons which push designers to investigate AM.

Secondly, we also noticed that creative designers, apart from AM, usually experience some intrinsic motivations and, moreover, that it exists an ideal state to generate creative concepts: the Flow. To support creative designers in DFAM in reaching the Flow, we then identified 4 key levers through the potential of AM : the newness of AM processes, the needed skill of 3D modelling, the investigation of new shape grammars and finally the opportunity of embodying concepts into physical objects.

To benefit from this potential, we assumed that designers' intrinsic motivations should be supported to reach the best conditions to generate creative concepts. We identified three required conditions. The first one is the use of a proper vocabulary i.e the expression Additive Manufacturing instead of $3 d$ Printing. The second one is the development of a design process which integrates a creative approach. The third condition is the use of AM objects as experience triggers during creative sessions to arise positive emotions.

It is worth to be mentioned, this paper is part of our current doctoral study. The questions and assumptions raised in this paper will be experimented in an industrial context during collective creative sessions, through Poly-Shape company and its industrial partners.

\section{References}


1. Rias AL., Segonds F., Bouchard C., Abed S. Design For Additive Manufacturing : a creative approach. in DESIGN 2016 conference, May 16-19th. 2016. Dubrovnik, Croatia.

2. AFNOR, NF E 67-001, 2011, Union de Normalisation de la Mécanique.

3. Rias AL., All the additive manufacturing processes : a graphic vizualisation 2016, http://strabic.fr/Impression-3d-ouFabrication-additive.

4. Wohlers Associates., ed. Additive manufacturing and 3D printing state of the industry. Annual worldwide progress report. 2013. 297.

5. Leandri A. Panorama des formations en fabrication additive en 2016. 2016 [cited 2016 October 27th ]; Training courses offers in France in 2016]. Available from:

http://souspression.canalblog.com/archives/2010/10/01/344772 44.html.

6. Segonds F., Cohen G., Véron P., Peyceré J., PLM and early stages collaboration in interactive design, a case study in the glass industry. International Journal on Interactive Design and Manufacturing (IJIDeM), 2016. 10(2): p. 95-104.

7. Hague R., Campbell I., Dickens P., Implications on design of rapid manufacturing. Journal of Mechanical Engineering Science, 2003. 217: p. 25-30.

8. Doubrovski Z. , Verlinden J., Geraedts J. Optimal design for additive manufacturing : opportunities and challenges. in ASME 2011 International Design Engineering Technical Conference \& Computer and Information in Engineering Conference. 2011. Washington DC, USA.

9. Alimardani M., Toyserkani E., Huissoon J. P, A 3D dynamic numerical approach for temperature and thermal stress distributions in multilayer laser Solid Freeform Fabrication process. Optics and Lasers in Engineering, 2007. 45: p. 1115-1130.

10. Rafi H. K., Starr T. L., Stucker B. E., A Comparison of the tensile, fatigue, and fracture behavior of Ti-6Al-4V and 15-5 PH stainless steel parts made by Selective Laser Melting International Journal of Advanced Manufacturing Technology, 2013. 69(5): p. 12991309.

11. Laverne F., Segonds F., Anwer N., Le Coq M., Assembly based methods to support product innovation in Design for Additive 
Manufacturing: an exploratory case study. Journal of Mechanical Design, 2015. 137(12): p. 121701.

12. Garcia R., Calantone R., A critical look at technological innovation typology and innovativeness terminology : a literature review.

Journal of Product Innovation Management, 2002. 19: p. 110-132.

13. Rosen D.W, Design for additive manufacturing : a method to explore unexplored regions of the design space., in 18th Annual Solid Freeform Fabrication Symposium2007. p. 402-4015.

14. Maheshwaraa U., Seepersad C., Bourell D. L., Design and Freeform Fabrication of Deployable Structures With Lattice Skins Rapid prototyping Journal, 2007. 13(4): p. 213-225.

15. Chu C. Graf G. and Rosen D., Design for Additive Manufacturing of cellular structures. Computer-aided design and applications, 2008. 5: p. 686-696.

16. Vayre B., Vignat F., Villeneuve F. Designing for Additive Manufacturing. in 45th CIRP Conference on Manufacturing systems 2012.

17. Ponche R., Hascoet JY., Kerbrat O., Mognol P., A new global approach to design for additive manufacturing. Virtual and physical prototyping, 2012. 7(2): p. 93-105.

18. Tang Y., Hascoet JV., Zhao YF., , Integration of topological and functional optimization in Design For Additive Manufacturing, in ASME 2014 12th biennal conference on Engineering systems2014: Copenhagen, Denmark.

19. Munguia J., Riba C., Lloveras J., In the search of design for rapid manufacturing strategies to solve functional and geometrical issues for small series production, in International Conference on Engineering Design ICED'072007: Paris, France.

20. Rodrigue H. Rivette M. An Assembly-Level Design for Additive Manufacturing Methodology. in IDMME-Virtual Concept. 2010. Bordeaux, France: Research in Interactive Design.

21. Boyard N., Rivette M., Christmann O., Richir S. A design methodology for parts using additive manufacturing. in 6th International Conference on Advanced research in Virtual and rapid prototyping. 2013. Leira, Portugal.

22. Burton M.J., Design for rapid manufacture : developping an appropriate knowledge transfer tool for industrial designers, 2005 , Faculty of Social Sciences \& Humanities department of Design \& Technology, Loughborough. 
23. Maidin B.S, Campbell I., Pei E., Development of a design feature database to support design for additive manufacturing. Assembly Automation, 2011. 32(3): p. 235-244.

24. Richard Ryan and Edward Deci, Intrinsic and Extrinsic motivations: classic definitions and new directions. Contemporary Educational Psychology, 2000. 25(1): p. 54-67.

25. Rieuf V., Impact of the immersive experience on Kansei during early design, in Engineering sciences2013, PHD thesis at Ecole Nationale Supérieure d'Arts et Métiers.

26. Oudeyer P-Y, Kaplan F. and Hafner V., Intrinsic Motivation Systems for Autonomous Mental Development. IEEE Transactions on Evolutionary Computation, 2007. 11(2): p. 265-286.

27. Bouchard C., Omhover JF., Kim J., Kansei information processes in early design, design cognition and computation. Emotional Engineering, ed. S. Fukuda. Vol. 3. 2014: Springer international publishing.

28. Csikszentmihalyi M. and Robinson R. E, The art of seeing: an interpretation of the aesthetic encounter. J. Paul Getty Museum. 1991.

29. Ocnarescu I., Aesthetic experience \& innovation culture : the aesthetic experience in an $R \& D$ department through design and for innovation culture, 2013, PhD thesis at Arts et Métiers Paristech.

30. Pei E., Campbell I., Evans M.A., Building a Common Ground - The Use of Design Representation Cards for Enhancing Collaboration between Industrial Designers and Engineering Designers, in Undisciplined! Design Research Society conference 16-19th july 2008.

31. Oxman R., Theory and design in the first digital age. Design Studies, 2006. 27: p. 229-265.

32. Kruth JP., Leu MC., Nakagawa T. Progress in Additive Manufacturing and Rapid Prototyping. 1998.

33. Systems, 3D. Good Morning America. 1989 [cited 2013 January 2013]; Available from: https://www.youtube.com/watch?v=9H1CUQ5U4Xc.

34. Bourell D., Beaman J., Leu M., Rosen D. A Brief History of Additive Manufacturing and the 2009 Roadmap for Additive Manufacturing: Looking Back and Looking Ahead. in RapidTech 2009. 2009. 
35. Ansburg P. I., Hill K., Creative and analytic thinkers differ in their use of attentional resources. Personality and Individual Differences, 2003. 34(7): p. 1141-1152.

36. Goldschmidt G., Smolkov M., Variances in the impact of visual stimuli on design problem solving performance. Design Studies, 2006. 27: p. 549-569.

37. Pasman G., Designing with precedents. 2003: Delft University of Technology.

38. Bonnardel N. Marmèche E., Towards Supporting Evocation Processes in Creative Design: A Cognitive Approach. International Journal Human-Computer Studies, 2005. 63: p. 422-435.

39. Byungun Yoon, Yongtae Park, A systematic approach for identifying technology opportunities: Keyword-based morphology analysis. Technological Forecasting \& Social Change, 2005. 72: p. 145-160.

40. Rias AL., Bouchard C., Segonds F., Abed S., Towards additive manufacturing of intermediate objects (AMIO) for creative concepts generation in DFAM, 2016: [not yet published at this date].

41. Mer, S., Jeantet, A., \& Tichkiewitch, S., Les objets intermédiaires de la conception: modélisation et communication. Le communicationnel pour concevoir, 1995: p. 21-41.

42. Cruz V., Gaudron N. Open-ended objects : a tool for brainstorming. 2010. Designing Interactive Systems conference Aarhus, Denmark, August 16-20th. 